Научная статья

УДК 81-25

DOI 10.18101/2686-7095-2021-2-16-25

\title{
ТИПОЛОГИЯ ОШИБОК В НЕПОДГОТОВЛЕННОМ ЧТЕНИИ НА РУССКОМ ЯЗЫКЕ КАК НЕРОДНОМ (на материале речи китайцев)
}

\author{
(C) Кун Чунься \\ аспирант, \\ Санкт-Петербургский государственный университет \\ Россия, 199034, г. Санкт-Петербург, Университетская набережная, 11 \\ kong.chunxia@mail.ru
}

\begin{abstract}
Аннотация. В статье рассматриваются речевые ошибки в русской речи китайцев. Возникновение таких ошибок связано, с одной стороны, с общей спонтанностью (неподготовленностью) устного речепорождения, с другой стороны - с ограниченным знанием информантами некоторых фактов неродного языка, с недостаточным уровнем владения этим языком. Делается попытка построения типологии ошибок в монологах чтения, записанных от носителей китайского языка. Было выделено четыре типа ошибок: акцентологические (полдЕнь, $p Е \kappa a$, сверхУ), лексико-грамматические (надевал вм. надевая, стираю вм. стирала), порождение квазислов (девяча вм. давеча, предтосла вм. предстояла) и контаминация фонетических и лексико-грамматических ошибок (слЕпая музыкант вм. слепой музыкант). В итоге оказалось, что на качество чтения влияют и содержание исходного стимула (лексико-грамматический набор единиц), и индивидуальные характеристики информантов: уровень владения русским языком, гендер и психотип. Встречаясь в тексте с трудными словами, информанты неосознанно извлекают из своего ментального лексикона наиболее близкие единицы, при этом часто срабатывает механизм замены, вследствие чего и возникают разнообразные ошибки. Устранение ошибок чтения в практике работы в иностранной аудитории возможно с помощью расширения словарного запаса учащихся, совершенствования знаний русской грамматики, а также развития навыков и умений собственно чтения как вида речевой деятельности.
\end{abstract}

Ключевые слова: монолог-чтение, устная спонтанная речь, типология ошибок, русский язык как иностранный

\section{Для цитирования}

Кун Чунься. Типология ошибок в неподготовленном чтении на русском языке как неродном (на материале речи китайцев) // Вестник Бурятского государственного университета. Филология. 2021. Вып. 2. С. 16-25.

Речевые ошибки как сложное явление рассматриваются в разных аспектах: психологическом, психо- и социолингвистическом, когнитивном и, конечно, собственно лингвистическом. С точки зрения лингвистики они считаются нарушением кодифицированных норм литературного языка. Как правило, наличие ошибок в речи является важным показателем речевой компетенции говорящего.

Интерес к речевым ошибкам в лингвистических исследованиях связан, прежде всего, с разработкой различных их классификаций (типологий), учитывающих, в частности, причины возникновения ошибки, соотношение ошибки с формой или типом речи, с уровнем языка и др. [19]. В большинстве таких исследо- 
Кун Чунься. Типология ошибок в неподготовленном чтении на русском языке как неродном (на материале речи китайцев)

ваний анализируются ошибки в речи носителей языка с целью осмысления причин их возникновения и их преодоления.

Однако изучение ошибок в русской речи иностранцев, в нашем случае в неподготовленном чтении китайцев, представляет собой не менее важную задачу лингводидактики и практического преподавания русского языка как иностранного. Такие ошибки чтения на русском как неродном языке заслуживают рассмотрения с разных сторон.

При рассмотрении разновидностей ошибок М. Р. Львов в одну группу объединяет ошибки чтения с ошибками орфографическими, пунктуационными, каллиграфическими, а также с опечатками и называет неправильное чтение слов неязыковой ошибкой [17]. Однако с такой позицией трудно согласиться. Неподготовленное чтение, помимо высокой степени лингвистической мотивированности исходным текстом, обладает и определенной степенью спонтанности, о чем, в частности, свидетельствует наличие в нем разнообразных примет спонтанно$c m u$, в том числе ошибок разного рода [13]. В случае чтения на неродном языке таких примет наблюдается даже больше, чем в чтении на родном языке. Кроме того, чтение как рецептивный вид речевой деятельности является многоуровневой задачей, требующей от говорящего (читающего) больших усилий для одновременного распознавания внешней формы (букв) и понимания текста. Другими словами, навыки и умения чтения, уровень языковой компетенции (уровень владения иностранным языком) оказывают существенное влияние на качество продукта чтения.

Г. А. Тезекбаева справедливо отмечает необходимость различать две группы ошибок: первая связана с «незнанием некоторого аспекта языковой системы», т. е. с ограниченным знанием языка в целом, а вторая - с «временным ослаблением внимания и контроля над речью» в ходе речепорождения, т. е. со спонтанной природой устной речи [23, с. 77]. На наш взгляд, вторая группа, прежде всего, связана с расширенным пониманием категории ошибок, к которой можно отнести самый широкий спектр примет спонтанности, обусловленных спецификой устного речепорождения. Количество таких ошибок в речи можно сократить, но практически нельзя до конца преодолеть (см., например, работы об ошибках в монологах чтения русских по-русски $\left.{ }^{1}[19 ; 20 ; 24 ; 1]\right)$. Однако борьба с первым типом ошибок идет постоянно, можно сказать, что она и есть процесс обучения русскому языку как иностранному. В ходе углубления знаний о неродном языке учащиеся постепенно преодолевают ошибки, связанные с недостаточным уровнем владения изучаемым языком.

В монологах чтения китайцев на русском языке были обнаружены разнообразные ошибки, и целью настоящего исследования стало построение их типологии, с учетом возможных причин возникновения, а также установление корреляции между типом ошибки и индивидуальными характеристиками информантов: гендером, психотипом и уровнем владения русским языком.

Материалом для исследования стали 40 монологов неподготовленного чтения на русском языке, записанных от 20 носителей китайского языка, поровну сюжетных (рассказ М. Зощенко «Рубашка фантази») и несюжетных (отрывок из

\footnotetext{
${ }^{1}$ Сервис оценки сложности русскоязычного текста. URL: http://pushkin-lab.ru (дата обращения: 14.03.2021). Текст: электронный.
} 
повести В. Короленко «Слепой музыкант») текстов. Все монологи входят в устный монологический корпус «Сбалансированная аннотированная текстотека» (САТ), разработанный в СПбГУ $[9 ; 4 ; 6]$.

Степень сложности исходных текстов была проверена с помощью программы оценки сложности русскоязычного текста для иностранной аудитории [21]. Согласно этой программе, уровень сложности текста М. Зощенко соответствует уровню владения русским языком В1; лексический минимум В2 покрывает 77 \% этого текста, а лексический минимум C1 - 85 \% текста. Уровень сложности несюжетного отрывка из текста В. Короленко соответствует уровню В2; лексические минимумы В1 и В2 покрывают лишь 60 \% этого текста, а лексический минимум C1 - $81 \%$ текста [14; 15]. Уже на этом основании можно предположить, что чтение несюжетного текста будет сложнее для китайцев и именно здесь можно ожидать больше ошибок.

Состав информантов, в число которых вошли студенты и аспиранты петербургских вузов в возрасте 23-28 лет, был сбалансирован по полу (10 юношей и 10 девушек) и по уровню владения русским языком (ТРКИ) (10 человек с ТРКИВ2 и 10 с ТРКИ-С1), согласно Российской государственной системе тестирования иностранных граждан ${ }^{1}$. Все информанты прошли также психологический тест Г. Айзенка $[26 ; 16]$ на китайском языке ${ }^{2}$. В результате в составе информантов было выявлено 5 экстравертов, 6 амбивертов и 9 интровертов.

Чтение является продуктом комплексного восприятия исходного материала и его репродукцией. Исходные тексты, предложенные информантам, содержали ряд сложных для чтения лексико-грамматических единиц, таких как незнакомые слова (теперича, давеча, фимиам), знакомые, но нечастотные слова (воротник, облачка, к завтрему, в аккурат), длинные слова (чистоплотный, двугривенный, колеблющийся, опрокинутый), имена собственные (Лукерья Петровна), идиомы и фразеологизмы (мать честная. ах чёрт! чёрт его знает! что за чёрт!). Кроме того, в зависимости от уровня владения русским языком и индивидуальных характеристик, читающие испытывали эти затруднения в разной степени и поразному реагировали на них [5].

В ходе неподготовленного чтения китайцев было выявлено 923 единицы ошибок, которые были разделены на четыре типа:

1) акцентологические (393, 42,6 \% общего количества ошибок);

2) лексико-грамматические $(240,26 \%)$, в том числе:

a. замена слова $(101,42$ \% от количества лексико-грамматических ошибок), бок),

b. замена словоформы $(139,58$ \% количества лексико-грамматических оши-

3) квазислова $(232,25,1 \%)$,

4) контаминация акцентологической и лексико-грамматической ошибки (58, $6,3 \%)$.

Рассмотрим получившуюся типологию подробнее.

\footnotetext{
${ }^{1}$ Уровень ТРКИ для каждого информанта был определен в их учебном заведении, специально для настоящего исследования тестирования не проводилось. URL: http://www.russia.edu.ru/rus/levels/ (дата обращения: 14.03.2020).

2 艾森克人格问卷（EPQ）（成人版） [Личностный опросник Г. Айзенка (EPQ) для взрослых]. URL: https://types.yuzeli.com/survey/epq85 (дата обращения: 14.03.2020).
} 
Кун Чунься. Типология ошибок в неподготовленном чтении на русском языке как неродном (на материале речи китайцев)

Акцентологические ошибки возникают в речи инофонов, как правило, в связи с ограниченным лексическим запасом. Информанты в процессе распознавания букв при чтении незнакомого или плохо знакомого слова определяют место ударения в нем по интуиции, с помощью экспорта смежного элемента из своего ментального лексикона ${ }^{1}$, ср.: давЕча (вечно), этАкую (этап), фантАзи (фантазия), ворОтниками (ворота), сверхУ (наверху), стирАная (стирать), полдЕнь (день), мУ-Узыкант (музыка), свЕркая (свет) (здесь и далее прописная буква обозначает неправильное ударение в слове, а повторение гласной буквы в слове $(y-y)$ означает растяжку соответствующего звука).

Кроме того, акцентологические ошибки могут возникнуть и в знакомых словах, включенных в лексические минимумы для В2 и С1. Здесь негативное влияние может оказать подвижный характер ударения в том или ином слове, ср.: $p E$ $\kappa а$, небесного иветА, врЕменами, отэ-э l ветрА и другие.

Несомненно, в связи с неподготовленностью речи и некоторым напряжением при выполнении речевого задания информанты могут поставить неуместное ударение в знакомых и простых словах даже и при отсутствии в них подвижного ударения, ср.: скАрее, горлО и др. С такими ошибками можно бороться лишь с помощью целенаправленного развития навыков чтения.

Некоторые информанты совершили акцентологическую ошибку при прочтении глагола в форме ср. p. прошедшего времени (билОсь). По опыту изучения русского языка такие ошибки можно объяснить следующим образом: при обучении РКИ преподаватели часто специально так прочитывают студентам подобные формы, чтобы они отличали формы ср. р. от форм ж. р., которые часто омофоничны. Студенты запоминают такое прочтение и затем повторяют его.

Лексико-грамматические ошибки. Исследователи давно заметили, что «коммуникативные потребности инофонов превосходят уровень их языковых

\footnotetext{
${ }^{1}$ Под ментальным лексиконом в лингвистике понимается как минимум словарный запас конкретной языковой личности, а как максимум - «сложная многоярусная система пересекающихся полей, представляющих собой упорядоченную по разным основаниям информацию как о явлениях действительности, так и о связанных с ними языковых единицах, сложную сеть взаимосвязей, увязывающую огромное количество знаний в памяти человека» [8, с. 87-88], или, иными словами, «“словарь в голове” индивида, функционирующий в соответствии с закономерностями психического развития человека - носителя языка и культуры» $[10$, с. 3]. Нет сомнения, таким образом, что «ментальный лексикон определяется не только словарем родного языка говорящего, но и всем его жизненным опытом, всей совокупностью его знаний об окружающей действительности. А значит, этот лексикон принципиально различен у разных людей и в целом не совпадает со словарем языка» [2, с. 57]. В последнее время изучение ментального лексикона, его устройства и функционирования выдвигается на первый план, оказываясь на пересечении интересов лингвистики и психологии. Ср. еще одно подходящее определение: ментальный лексикон - это «сеть, в которой каждое слово связано со всеми другими» [11, с. 85]. Исследования ментальных лексиконов посвящены, прежде всего, «выяснению принципиальных вопросов: как извлекаются из памяти слова, как они в ней репрезентированы и организованы; как взаимодействуют лингвистические и психологические факторы при формировании репрезентации лексического знания и обеспечении лексической обработки в реальном времени» $[7$, с. 7-8]. В практике преподавания РКИ все эти моменты нужно непременно учитывать.
} 
возможностей», и поэтому они склоны упрощать парадигмы грамматического склонения или спряжения и подсознательно выбирают те единицы, которые «прочнее вписаны в их ментальный лексикон» [26]. А ментальный лексикон человека часто связан с более частотными словами или словоформами. По способу замены были выделены следующие подтипы лексико-грамматических ошибок.

(1) Замена слова более частотным или более привычным, но близким по орфографии и, соответственно, по звучанию, ср.: аккаунт вм. аккурат, лодке вм. локтях, у меня вм. у нас, отхода вм. охота, подробно вм. подобно, лимонами вм. лиманами, дальше вм. дальние, не боюсь вм. небось, принято вм. приятно.

(2) Замена словоформы более частотной (привычной) грамматической формой:

а) замена словоформы начальной формой слова: бухгалтер вм. бухгалтеру, говорить вм. говорит;

б) замена словоформы другой формой того же слова: надевал вм. надевая, стираю вм. стирала, таяло вм. таяли;

в) замена словоформы другим вариантом той же формы: чтобы вм. чтоб, поскорее вм. поскорей, покрасивее вм. покрасивей.

В последнем случае замена происходит, как правило, по принципу: разговорная форма $\rightarrow$ литературная форма. Видно, что литературные формы знакомых слов иностранные студенты знают хорошо, в то время как с разговорными оказываются порой совсем не знакомы.

Контаминация фонетических и лексико-грамматических ошибок. Нередко в ходе чтения информант допускает в одном слове сразу две ошибки: например, заменяет букву/слово/словоформу и ошибается в ударении, ср.:

(1) смешение/замена/добавление букв и неправильное ударение: девАча вм. давеча; ЖУ-укерья вм. Лукерья; фан-тАнзи вм. фантази; бордУ вм. морду;

(2) смешение словоформ/слов и неправильное ударение: слEпая музыкант вм. слепой музыкант.

Квазислова. Квазислово (от лат. quasi — 'как будто, будто бы') словари трактуют через значение приставки квази- — 'мнимый, ненастоящий' [22, с. 43]. Такие мнимые, не существующие в языке единицы встречаются в речи как ионофонов, так и русских [3]. Квазислова в естественной речи (в отличие от тех, что создаются намеренно для какого-либо лингвистического эксперимента [12]) часто рождаются путем искажения полноценного слова, что отражается на фонетическом уровне, реже - с опорой на возможный словообразовательный потенциал лексем. В ходе анализа материала в нашем исследовании были выделены следующие разновидности таких единиц:

(1) замена звука в слове (заскочал вм. заскочил, теперила вм. теперича, кидайцы вм. кидаться, девеча / девяча вм. давеча);

(2) добавление звука в слове (давечка вм. давеча, стирарная вм. стираная, рябрь вм. рябь);

(3) пропуск звука в слове (бухалтер вм. бухгалтер, сутно вм. смутно, деткое вм. детское, сломой вм. соломой);

(4) перестановка звуков в слове (без махства вм. без хамства);

(5) контаминация вышеупомянутых типов (проснела вм. пронесла, крастинка вм. картинка, предтосла вм. предстояла). 
Кун Чунься. Типология ошибок в неподготовленном чтении на русском языке как неродном (на материале речи китайцев)

Видно, что подобные единицы не слишком отличаются от приведенных выше девАча, ЖУ-укерья, фан-тАнзи или бордУ, которые были расценены как ошибки определенного типа. Можно согласиться с мнением Н. В. Богдановой-Бегларян, что «вопрос о разграничении этих трех понятий (ошибка, оговорка и квазислово. - Ч. К.) еще ждет своего теоретического осмысления» [3, с. 1235].

Корреляции с характеристиками говорящих/читающих и типом текста. Анализ материала показал, что ошибки в русской речи иностранцев разнообразны и многочисленны, особенно в том случае, когда они без подготовки читают незнакомый текст. Причины появления ошибок связаны, с одной стороны, со спонтанностью устной речи, с другой стороны, с недостаточным владением информантами русским языком.

Более того, при рассмотрении корреляций между индивидуальными характеристиками читающего и количеством ошибок обнаружилось, что информантыюноши ошибались чаще, чем девушки, вне зависимости от типа текста $(55,4$ vs 44,6 \%); а информанты с уровнем C1 (более высокий уровень владения русским языком) в целом совершили ошибок чуть больше, нежели информанты с уровнем В2 (более низким) (51,9 vs 48,1 \%). Это можно объяснить, вероятно, более высоким темпом речи тех учащихся, кто чувствует себя в русском языке более уверенно. При высокой скорости чтения они могут чаще ошибаться и не всегда замечать сделанную ошибку. Правда, акцентологических ошибок оказалось больше именно в речи информантов с более низким уровнем ТРКИ-В2: 52,4 vs 47,6 \% в речи группы с уровнем $\mathrm{C} 1$.

В речи информантов-интровертов обнаружилось меньше квазислов $(29,2 \%)$, чем в речи амбивертов и экстравертов (40,5 и $30,2 \%)$.

Вопреки ожиданиям, чтение сюжетного текста выявило больше речевых ошибок, чем чтение несюжетного, хотя в целом примет спонтанности оказалось больше в монологах чтения именно несюжетного текста [13].

Самым популярным типом ошибок в монологах чтения носителей китайского языка оказались акцентологические (42,6\%).

Дополнительная типология ошибок. В научной литературе существует еще классификация ошибок по реакции на них информанта [20; 25; 9]:

1) ошибки замеченные и исправленные: см. ниже примеры (1), (2), (3),

2) ошибки замеченные и неисправленные: (4),

3) ошибки не замеченные и, соответственно, неисправленные: (5), (6).

Первый тип можно толковать как случаи самокоррекциии, когда информант, заметив ошибку, моментально (онлайн) либо после короткой передышки (офлайн) исправляют речевой сбой ${ }^{1}$. Хотя результат такой самокоррекции может быть не всегда удачным. В случае неудачной самокоррекции обычно образуется цепочка ошибок, ср.:

\footnotetext{
${ }^{1}$ Надо отметить, что офлайн-коррекции в речи информантов-китайцев (равно как и других иностранцев) встречаются достаточно редко. Возможно, это обусловлено тем, что в ходе речевой деятельности на неродном языке оперативная память говорящего гораздо короче, чем в речи на родном языке: он попросту не способен долго помнить о сделанной и даже замеченной ошибке.
} 
1) завтра-а l вечЕрника l вечеринка // надо кэ завтра l надо к завтрему;

2) не лезёт / не лезет / не лезёm 忘了<забыла (перевод мой. -Ч. К.)>;

3) за рекой / чернели ll р... разопревшие нивЫ // и парили // застилая ll реЮщею / колеблЮ... / колеблЮщ... I колеблЮмеюсь лЮ... колеблЮмеюся l дымкой дальиие ll лАчиги ll;

4) на-а вечеринке l думаю / все l барБини l ки-даться будут;

5) в воскресИнье у нас / вечеринка l предстояла;

6) вот примерИл эту рубаху / и как-то не п[о] себе стало.

В контексте (1) информант прочитал слово вечеринка с ошибкой, заметил это, о чем свидетельствует пауза хезитации, и исправил себя. В том же контексте он прочитал кэ завтра вместо к завтрему и, начав фразу с начала, исправил ошибку и вышел таким образом из «точки сбоя».

В контексте (2) информант засомневался в прочтении слова лезет, но, колеблясь между правильным и неправильным вариантами, остановился все же на неправильном (лезёт). Причину колебания информант сам объяснил в метакоммуникативной вставной конструкции на китайском языке: он забыл правильное ударение в этом слове.

В примере (3) хорошо видно, что информант не знает слова колеблющиийся: он несколько раз пробовал его прочитать, но так и не справился с длинным незнакомым словом, в результате получилась цепочка ошибок.

Все ошибки в приведенных примерах однозначно замечены информантами, во всех случаях сделана попытка их исправить, хотя и не всегда удачная.

В примере (4) информант тоже заметил ошибку, о чем свидетельствует недолгая хезитационная заминка, но не стал ее исправлять и продолжил чтение. Стоит отметить, что разного рода хезитации часто выступают показателем того, что ошибка говорящим замечена.

В последних контекстах (5)-(6) информанты сделали ошибки (подчеркнуты), которых, по-видимому, не заметили, поскольку продолжили чтение без всяких хезитаций. Такие ошибки, разумеется, остаются неисправленными.

Приведенный анализ корпусного материала позволяет утверждать, что в русской речи иностранцев встречаются ошибки разного типа, в том числе и тогда, когда они без подготовки читают незнакомый текст. Появление ошибок связано, с одной стороны, со спонтанностью устной речи (это свойственно и речи на родном языке), а с другой стороны, с недостаточным уровнем владения русским языком (свойственно, как правило, только иностранцам). Помимо того, на качество чтения влияют тип текста (его сюжетность/несюжетность) и навыки чтения, которыми обладают информанты. Ошибки бывают фонетические (акцентологические и порождение квазислов) и лексико-грамматические (замена слова или словоформы). Преодоление этих ошибок на уроках русского языка в иностранной аудитории может, соответственно, идти двумя путями: изучение словаря и грамматики (повышение уровня владения языком) и развитие навыков устной речи.

\footnotetext{
1 Здесь и далее знак (l) обозначает физическую паузу хезитации, двойной (ll) - более длительную паузу хезитации.
} 
Кун Чунься. Типология ошибок в неподготовленном чтении на русском языке как неродном (на материале речи китайцев)

Лuтература

1. Баева Е. М. Хезитационные явления в устных монологах низкой степени спонтанности // Коммуникативные исследования. 2018. № 1 (15). С. 75-84. Текст: непосредственный.

2. Богданова Н. В. Русское слово в трех режимах фиксации - словарь, ментальный лексикон и реальное употребление (лексикографический и лингвометодический аспекты) // Русский язык за рубежом. 2011. № 6 (229). С. 56-64. Текст: непосредственный.

3. Богданова-Бегларян Н. В. Ошибка - оговорка - квазислово: размышления о сходствах и различиях // Наука СПбГУ - 2020: сборник материалов всероссийской конференции по естественным и гуманитарным наукам с международным участием. СанктПетербург: Скифия-принт, 2021. С. 1234-1235. Текст: непосредственный.

4. Богданова-Бегларян Н. В., Шерстинова Т. Ю., Зайдес К. Д. Корпус «Сбалансированная Аннотированная Текстотека»: методика многоуровневого анализа русской монологической речи // Анализ разговорной русской речи ( $\left.\mathrm{AP}^{3}-2017\right)$ : труды Седьмого междисциплинарного семинара / науч. ред. Д. А. Кочаров, П. А. Скрелин. Санкт-Петербург: Политехника-принт, 2017. С. 8-13. Текст: непосредственный.

5. Корпус «Сбалансированная аннотированная текстотека» (САТ): изучение специфики русской монологической речи / Н. В. Богданова-Бегларян, О. В. Блинова, К. Д. Зайдес, Т. Ю. Шерстинова // Труды Института русского языка им. В. В. Виноградова / гл. ред. А. М. Молдован. Вып. 21. Национальный корпус русского языка: исследования и разработки / ответственный редактор выпуска В. А. Плунгян. Москва: Институт русского языка РАН, 2019. С. 111-126. Текст: непосредственный.

6. Богданова-Бегларян Н. В., Кун Чунься. «Стратегии» прочтения незнакомого русского слова носителями китайского языка // Социо- и психолингвистические исследования. 2020. № 8. С. 32-39. Текст: непосредственный.

7. Глазанова Е. В. Типы связей в ментальном лексиконе и экспериментальные методы их исследования: диссертация на соискание ученой степени кандидата филологических наук. Санкт-Петербург, 2001. 237 с. (машинопись). Текст: непосредственный.

8. Залевская А. А. Слово в лексиконе человека: Психолингвистическое исследование. Воронеж: Изд-во Воронеж. ун-та, 1990. 205 с. Текст: непосредственный.

9. Звуковой корпус как материал для анализа русской речи: коллективная монография. Ч. 1. Чтение. Пересказ. Описание / ответственный редактор Н. В. БогдановаБегларян. Санкт-Петербург: Филологический фак-т СПбГУ, 2013. 532 с. Текст: непосредственный.

10. Золотова Н. О. Ядро ментального лексикона человека как естественный метаязык: автореферат диссертации на соискание ученой степени доктора филологических наук. Тверь, 2005. 44 с. Текст: непосредственный.

11. Караулов Ю. Н. Русский язык и языковая личность. Москва: Наука, 1987. 264 с. Текст: непосредственный.

12. Королева И. В. Роль лингвистических факторов в развитии процессов чтения (экспериментальное исследование на материале русского языка): диссертация на соискание ученой степени кандидата филологических наук. Санкт-Петербург, 2006. 227 с. (машинопись). Текст: непосредственный.

13. Кун Чунься. Неподготовленное чтение как разновидность спонтанной речи (о приметах спонтанности в чтении на неродном языке) // Вестник Перм. ун-та. Российская и зарубежная филология. 2021 (в печати).

14. Лексический минимум по русскому языку как иностранному. 2-й сертификационный уровень. Общее владение / редактор Н. П. Андрюшина. Санкт-Петербург: Златоуст, 2011. 164 с. Текст: непосредственный. 
15. Лексический минимум по русскому языку как иностранному. 1-й сертификационный уровень. Общее владение / редактор Н. П. Андрюшина. Санкт-Петербург: Златоуст, 2015. 200 с. Текст: непосредственный.

16. Личностный опросник ЕРI (методика Г. Айзенка) // Альманах психологических тестов / составители и редакторы Р. Р. Римский, С. А. Римская. Москва: КСП, 1995. С. $217-$ 224. Текст: непосредственный.

17. Львов М. Р. Словарь-справочник по методике русского языка. Изд. 2-е, испр. и доп. Москва: Академия, 2001. 256 с. Текст: непосредственный.

18. Словарь русского языка: в 4 томах. Т: II. К-О / редактор А. П. Евгеньева. Изд. 3-е, стер. Москва: Русский язык, 1986. 736 с. Текст: непосредственный.

19. Рыженко Ю. А. К проблеме классификации речевых ошибок // Научные труды КубГТУ. 2016. № 6. С. 290-298. Текст: непосредственный.

20. Сапунова Е. М. Лингвистические особенности неподготовленного чтения как вида речевой деятельности // Вестник Санкт-Петербургского университета. Серия 9. Филология. Востоковедение. Журналистика. Вып. І. Ч. ІІ. 2009. С. 161-168. Текст: непосредственный.

21. Сапунова Е. М. Неподготовленное чтение как вид речевой деятельности и тип устного спонтанного монолога (на материале русского языка): диссертация на соискание ученой степени кандидата филологических наук. Санкт-Петербург, 2009. 237 с. (машинопись). Текст: непосредственный.

22. Степихов А. А. Чтение текста: норма и реализация // Фонетика в системе языка: тезисы ІІІ Международного симпозиума МАПРЯЛ. Москва: Изд-во РУДН, 2002. С. 8586. Текст: непосредственный.

23. Тезекбаева Г. А. Спонтанная речь как объект лингвистики // Вестник Воронежского государственного университета. Серия: Филология. Журналистика. 2011. № 1. С. 7679. Текст: непосредственный.

24. Хан Н. А. Заметить / не заметить, исправить / не исправить: анализ ошибок неподготовленного чтения (на материале Звукового корпуса русского языка) // Русская филология. 23: сборник научных трудов молодых филологов. Тарту: Тарт. ун-т, 2012. С. 208215. Текст: непосредственный.

25. Цейтлин С. Н. Грамматические ошибки в освоении русского языка как первого и как второго // Вопросы психолингвистики. 2009. № 9. С. 43-53. Текст: непосредственный.

26. Eysenk, H. J., Eysenk, S. B. G. Manual of the Eysenck Personality Inventory. London: Univ. of London press, 1964. 24 p. Текст: непосредственный.

Статья поступила в редакцию 24.03.2021; одобрена после рецензирования 30.05.2021; принята к публикации 30.06.2021.

\section{TYPOLOGY OF MISTAKES IN UNPREPARED READING \\ IN RUSSIAN AS FOREIGN LANGUAGE \\ (on material of speech of the Chinese)}

Kong Chunxia

postgraduate student,

St. Petersburg State University

11 Universitetskaya emb., St. Petersburg 199034, Russia

kong.chunxia@mail.ru

Abstract. The article reviews errors in the Russian speech of the Chinese people. The occurrence of such errors is associated, on the one hand, with the general spontaneity (unprepar- 
Кун Чунься. Типология ошибок в неподготовленном чтении на русском языке как неродном (на материале речи китайцев)

edness) of oral speech, on the other hand, with limited knowledge of a non-native language by the informants, with an insufficient level of proficiency in this language. The paper attempts to construct a typology of errors in reading monologues recorded by native Chinese speakers. Four types of errors are identified: accentological (poldEn', rEka, sverhU), lexicogrammatical (nadeval instead of nadevaja, stiraju instead of stirala), creation of quasiwords (devjacha instead of davecha, predtosla instead of predstojala) and contamination of phonetic and lexical-grammatical mistakes (slEpaja muzykant instead of slepoj muzykant). As a result, it turned out that the quality of reading is influenced by both the content of the initial stimulus (lexical and grammatical set of units) and the individual characteristics of the informants: the level of Russian language proficiency, gender and psychotype. When facing with difficult words in a text, informants unconsciously extract the closest units from their mental vocabulary, and often a replacement mechanism is triggered for them, leading to various errors. Elimination of reading errors is possible by expanding the students' vocabulary, improving the knowledge of Russian grammar, as well as developing the skills and abilities of reading itself as a type of speech activity.

Keywords: reading monologue; oral spontaneous speech; typology of mistakes; Russian as foreign language.

\section{For citation}

Kong Chunxia. Typology of mistakes in unprepared reading in Russian as foreign language (on material of speech of the Chinese). Bulletin of Buryat State University. Philology. 2021; 1: 16-25 (In Russ.).

The article was submitted 24.03.2021; approved after reviewing 30.05.2021; accepted for publication 30.06.2021. 